1 Impact of anti-ageing compounds on oxidation ageing kinetics of bitumen by

2 infrared spectroscopy analysis ${ }^{1}$

\section{Eman L. Omairey}

PhD Student

Aston Institute of Materials Research

Aston University, Aston Triangle, Birmingham B4 7ET, UK

Email: omaireye@,aston.ac.uk

Yuqing Zhang, $\mathrm{PhD}$

Lecturer in Highway Engineering

Aston Institute of Materials Research

Aston University, Aston Triangle, Birmingham B4 7ET, UK

Tel: +44(0)-121-204-3391, Email: y.zhang10@aston.ac.uk

(Corresponding Author)

Sahar Al-Malaika, $\mathrm{PhD}$

Professor

Polymer Processing and Performance Research Group

School of Engineering and Applied Science

Aston University, Aston Triangle, Birmingham B4 7ET, UK

Tel: +44 (0)-121-204-3372, Email: s.al-malaika@,aston.ac.uk

Husam Sheena, $\mathrm{PhD}$

Senior Research Fellow

Polymer Processing and Performance Research Group

School of Engineering and Applied Science

Aston University, Aston Triangle, Birmingham B4 7ET, UK

Tel: +449(0)-0121-204-3421, Email: h.h.sheena@aston.ac.uk

Fan Gu, PhD

Marie Curie Research Fellow

Aston Institute of Materials Research

Aston University, Aston Triangle, Birmingham B4 7ET, UK

Email: f.gu1@aston.ac.uk

\footnotetext{
${ }^{1}$ This is an Accepted Manuscript of an article to be published by Journal of Construction and Building Materials. Access to the full text of the paper is available at https://doi.org/10.1016/j.conbuildmat.2019.07.021
} 
Omairey, Zhang, Al-Malaika, Sheena, Gu

\section{Abstract}

38 This paper investigates the effect of different anti-ageing compounds (AACs) on the oxidation

39 kinetics of bitumen using Fourier Transformation Infrared (FTIR) spectroscopy. Twenty different

40 AACs were examined, including new and existing AACs for bitumen and polymer products. The

41 AACs were mixed with bitumen to fabricate thin film samples of AAC-modified bitumen which

42 were subjected to laboratory oven ageing at $100{ }^{\circ} \mathrm{C}$ with different ageing periods up to 504 hours.

43 A Normalized Carbonyl Index (NCI) was proposed based on a selected reference peak $\left(1377 \mathrm{~cm}^{-}\right.$

$4 \mathrm{~S}^{1}$ ) to eliminate the impact of the inherent carbonyl content from the bitumen or AACs and manifest

45 the carbonyl growth rate for evaluating the AACs' anti-ageing performance. It was found the 46 activation energy of fast-term oxidation can be utilized to quantitatively screen the anti-ageing

47 compounds and evaluate their anti-ageing effectiveness in terms of decreasing the formation of 48 carbonyl groups in bitumen. AACs that exhibited high anti-ageing performance were those 49 contained furfural, Irganox acid with sodium montmorillonite, furfural with DLTDP, and high 50 concentrations (e.g., 15\%) of Irganox acid. The proposed protocol should be followed by further 51 laboratory rheological and mechanical tests on the AAC-modified bitumen with different binder 52 sources.

54 Keywords: Ageing of bitumen, Anti-ageing compounds, Oxidation kinetics, FTIR, Oven ageing, 55 Carbonyl index 
Omairey, Zhang, Al-Malaika, Sheena, Gu

\section{Introduction}

Ageing of bitumen is identified by the increase in its stiffness which causes adverse changes to the mechanical performance of roads and eventually leads to ageing failure in a form of thermal or fatigue cracking. Oxidative ageing of the bitumen is typically quantified by the development of carbonyl functional groups using Fourier Transformation Infrared Spectroscopy (FTIR) test [1]. This is fundamentally due to the fact that a linear relationship exists between the carbonyl content formed and the oxygen absorbed by the bitumen. A correlation also exists between the bitumen's hardening susceptibility and the carbonyl content [2]. Wide range of FTIR applications for bitumen exist. FTIR applications include materials and ageing recognition. Additionally, researchers utilized FTIR to examine the interaction between the bitumen and modifiers and the moisture effects on ageing [3-5]. A detailed explanation for these functions is listed in the literature [6].

For ageing recognition and quantification, researchers have established different parameters to characterise the carbonyl-growth, one of which is carbonyl area $(C A)$ that is defined as the integral area under the absorbance curve from FTIR tests within a wavelength range from 1820 to $1650 \mathrm{~cm}^{-1}$ [7]. The carbonyl area was intensively used to quantify the ageing performance of the bitumen; however, it has limitations in comparing the modified binders when the additives themselves contain carbonyl functional groups in their primary chemical form and may change during the ageing process [5]. Additionally, the fixed wavelength range $\left(1820\right.$ to $\left.1650 \mathrm{~cm}^{-1}\right) \mathrm{can}$ cause inaccuracy in the calculation of the carbonyl area due to the changes encountered in the absorbance wave pattern within that range. This case is more pronounced when bitumen lacks carbonyl prior to ageing. This can lead to a negative value in the carbonyl area, as shown in the following sections. Herrington (2012) measured the normalized carbonyl area in a range from 1640 to $1810 \mathrm{~cm}^{-1}$ and divided it by the area under $1600 \mathrm{~cm}^{-1}$ peak (using $1810 \mathrm{~cm}^{-1}$ as a baseline), to solve the variations in sample concentration [8]. Liu et al. (2015) introduced a carbonyl index as the ratio of carbonyl area under $1700 \mathrm{~cm}^{-1}$ peak to that of methylene group under $1375 \mathrm{~cm}^{-1}$ peak to eliminate the effect of bitumen sample thickness on the carbonyl area [9]. Another adopted method was to divide the carbonyl area under the $1700 \mathrm{~cm}^{-1}$ peak by the summation of all absorbance areas for the bitumen [10] or a portion of it [11]. Similarly, the sulfoxide index (which is an additional oxidation measure), was calculated by the same procedures but under a peak of $1031 \mathrm{~cm}^{-1}$. It can be seen that there is no agreed or consistent method to determine the carbonyl content and the decision was rather arbitrary depending on individual choices.

The attempt to characterize the ageing quantity of modified bitumen binders such as SBS polymer modified binders by carbonyl formation is another complication. This led to adopting a new set of testing methods and conditions [12]. Few attempts were made to address this issue [4]. Zhao et al. (2010) studied the ageing characteristics and materials interaction of polymer modified bitumen using two carbonyl parameters [13]. One was using carbonyl index to study ageing properties of the bitumen-polymer blend. The second parameter was carbonyl area to address the changes occurring in polymer and base bitumen individually. However, no justification was provided for using those two parameters. Therefore, it is difficult to compare the ageing resistance for the bitumen with different modifiers subjectively. Furthermore, it is unclear which FTIR parameter is effective to rank the anti-ageing compounds' (AACs) performance in reducing ageing of the bitumen. Reasons for this attributed to the adoption of various ageing conditions (such as 
short-term ageing, long-term ageing, different temperatures and pressure conditions), evaluation criteria (rheological properties or chemical changes), and parameter used (ageing indices).

Many AACs were tested to enhance the bitumen's mechanical performance and long-term durability, and the work in this area also continues due to the persistent new findings and AACs developed. While extensive work is available to model the viscoelastic asphalt mixtures and aggregate structures $[14,15]$, the ageing characterization the bitumen binders modified by AACs are needed in order to develop a comprehensive multi-physical model for the durability prediction of the asphalt mixtures in the field. Furthermore, linking the mechanical performance with the oxidation kinetics will produce a reliable integrated pavement performance model. Thus, a consistent primary selection criterion is very needed for screening these anti-ageing compounds and the effect of the AACs on the ageing kinetics of bitumen requires further studies, particularly for those AACs with inherent carbonyl functional groups.

In summary, the purpose of this paper is to develop a unified AAC screening method and consistent ageing parameters to evaluate the anti-ageing performance of different types of AACs and comparing the ageing kinetics of the bitumen modified by those AACs.

\section{Materials and Testing Methods}

A type of bitumen, classed as a 40/100 according to BSEN14023:2010 for general asphalt applications and road constructions, was used as a base (control) binder to examine the effect of adding AACs, where Table 1 lists its engineering specifications. The reason behind examining a single type of bitumen was to withdraw binder-source effects on the AAC results. Others have used a similar approach to neglect the binder type variances on ageing kinetics [9, 11, 16 and 17].

\section{TABLE 1 Conventional properties of the control binder}

\begin{tabular}{|l|l|}
\hline Property & Value \\
\hline Penetration @ $25^{\circ} \mathrm{C}(0.1 \mathrm{~mm})$ & $45-80$ \\
\hline Softening Point $\left({ }^{\circ} \mathrm{C}\right)$ & $\geq 45$ \\
\hline Flash Point $\left({ }^{\circ} \mathrm{C}\right)$ & $>250$ \\
\hline Force Ductility @ $5^{\circ} \mathrm{C}\left(\mathrm{J} / \mathrm{cm}^{2}\right)$ & $>3$ \\
\hline
\end{tabular}

Nomination of AACs was based on four aspects: 1) materials that proved effective in previous researches but require further investigations, 2) new polymer modifiers that have not been tested on bitumen binders before, 3) different multifunctional nanomaterials (materials in nanoscale size range in at least one dimension, that could work as exfoliators/intercalators, hydroxyl groups providers, metal fillers, etc,..), and 4) some common bitumen AACs that were added for comparison. The selected AAC compounds vary in their anti-oxidation functionality, structure and chemical behaviour, this is to ensure the study covers a wide range of anti-ageing materials. The concentrations of AACs were based on two aspects, namely, the availability of materials to be used in large quantities, and the previous literature available concerning each additive's expected reaction. Some additives were tested at different concentrations. A list of AACs and their concentrations are summarized in Table 2. Details of each additive are provided below.

Furfural (2-Furaldehyde) with (Dilauryl) Thiodipropionate (DLTDP) (didodecyl 3, 3'thiopropionate) compound was investigated by Apeagyei (2011) in terms of the rheological properties of the binder. A percentage of 3.5\% (4:3 furfural: DLTDP) achieved 40\% reduction in 
138 the ageing hardening of modified binders compared with unmodified binders. However, the chemical properties and ageing kinetics were not investigated [14].

No researches were found on the use of Irganox 1076 (Octadecyl-3-(3,5-di-tert. butyl-4hydroxyphenyl)-propionate) for bitumen. Irganox 1076 is a commercial polymer additive with low volatility, good resistance to extraction and thermo-oxidative degradation (the process of oxygencontaining groups formation that occurs under the comprehensive effects of light, heat and 144 oxygen).

In addition, two other types of Irganox additives were tested, MD1024 and Irganox acid. MD 1024 (Benzenepropanoic acid, 3,5-bis(1,1-dimethylethyl)-4-hydroxy-, 2-[3-[3,5-bis(1,1dimethylethyl)-4-hydroxyphenyl]-1-oxopropyl] hydrazide) is used for protection against metals and minerals contamination at high temperatures. Whereas, Irganox acid is a hindered phenol organic (3,5-di-tert-butyl-4-hydroxyphenylpropionic acid) that has been synthesized at Aston University Chemical Engineering laboratories and currently being tested as a polymer antioxidant.

Hydrated lime has been included for comparison purposes in the testing program as it is a common AAC for bitumen [19-23]. It is known for reducing the rate of age hardening. This reduction is attributed to the absorption by lime of asphalt components that otherwise would have increased the sensitivity of the asphalt to the oxidation products [22]. The use of emulsifiers such as lime is a common practice especially in cold recycled asphalt pavements [24]. The end result of using lime emulsifier is hydrated lime. Therefore, it has been included as one of the AAC in this study.

Nanomaterials such as Cloisite C20A, bentonite HCT and sodium montmorillonite were included in the testing program. Ghli (2006), Ortega et al. (2017), Kumar and Suman (2017), Hassan et al., (2012) and Yao et al., (2013) reported the beneficial effects of adding nanomaterials to bitumen. The benefits of those AACs include the increase of bitumen's thermal stability, resistance against permanent deformations and strengthening of bitumen's bonding with rubber modifiers. Furthermore, these AACs are believed to decrease the oxygen diffusion during ageing. However, debate exists on whether these improvements can justify their applications on wider range conditions in the field [25-29].

Other additives were also tested, such as tetramethyl thiuram disulphide, TRIS and trimethylolpropane. tetramethyl thiuram disulphide is used as a polymerization initiator and accelerator in rubber industry [30]. TRIS (hydroxymethyl-aminomethane), according to Wilkes and Davies (2010)) can be used as a dispersant for asphaltene inhibition of hydrocarbon fluids such as bitumen and crude oil [31]. Whereas, trimethylolpropane is a stable compound under different environmental and light exposure conditions and was included due to its ability to reduce oxidation of trimethylolpropane esters based on palm oil and palm kernel oils [32]. The technical and safety properties of these materials are listed in the manufacturers' technical and safety datasheets. Dealing with furfural is considered hazardous to human health, which requires special measures during the mixing processes in the field outside the laboratory-controlled conditions.

TABLE 2 Anti-ageing compounds and concentrations.

\begin{tabular}{|l|l|}
\hline Additive & $\begin{array}{l}\text { The concentration of additive added } \\
\text { (\% by mass of bitumen binder) }\end{array}$ \\
\hline Irganox acid & $5,10,15$ \\
\hline Tetramethylthiuram disulphide & 1 \\
\hline
\end{tabular}


Omairey, Zhang, Al-Malaika, Sheena, Gu

\begin{tabular}{|l|l|}
\hline Cloisite C20A & 10 \\
\hline Bentonite HCT & 10 \\
\hline Sodium montmorillonite & 10,15 \\
\hline TRIS (hydroxymethyl-aminomethane) & 5,10 \\
\hline Calcium hydroxide & 10 \\
\hline $\begin{array}{l}\text { (3:1:1) TRIS (hydroxymethyl-aminomethane): bentonite: } \\
\text { calcium hydroxide }\end{array}$ & 10 \\
\hline Irganox 1076 & 15 \\
\hline MD1024 & 0.1 \\
\hline (3:2) sodium montmorillonite: Irganox acid & 25 \\
\hline (1:1) calcium hydroxide: TRIS (hydroxymethyl-aminomethane) & 20 \\
\hline (4:3) furfural: DLTDP ((Dilauryl) Thiodipropionate) & 3.5 \\
\hline Furfural & 2 \\
\hline (1:5) furfural: Irganox 1076 & 12 \\
\hline Trimethylolpropane TMP & 10 \\
\hline
\end{tabular}

Testing samples were prepared by mixing the additives with bitumen (mass of bitumen samples 1-3 g) using solvent blending method, i.e., mother liquor melting ( $\mathrm{Li}$ et al (2017)) to achieve better dispersion of the AACs into bitumen, as well as, due to the nature of FTIR testing which requires placing a thin-film sample on a sodium chloride testing plate [33]. Dichloromethane was used as a solvent for its high bitumen dissolving ability at low temperatures such as at room temperature, high evaporation rate and low viscosity [10], while others used solvents such as kerosene due to its low cost and availability [33].

Samples were prepared by mixing additives, bitumen and equal concentrations of dichloromethane by means of an ultrasonic shaker for at least 30 minutes to ensure complete dispersion at room ambient temperature $\left(20^{\circ} \mathrm{C}\right)$.

Afterwards, a thin-film sample (thickness of $0.5 \mathrm{~mm}$ ) was laid on a newly polished salt plate sitting in a metallic frame to be scanned under the FTIR. The solvent was left to evaporate in a nitrogen environment, and then it was placed in a temperature-controlled oven at $100{ }^{\circ} \mathrm{C}$ for 10 minutes to make sure complete evaporation of the solvent is achieved. A similar ageing approach was used to characterize the ageing of bio-bitumen modified by pyrolysis oils derived from the municipal solid waste [34].

Temperature-controlled oven at $100^{\circ} \mathrm{C}(373.15 \mathrm{~K})$ under atmospheric air conditions $(0.2$ atm oxygen pressure) was used to age the thin-film specimens for extended periods of time up to $504 \mathrm{~h}$. FTIR spectroscopy tests were carried out at different ageing periods including 0 (unaged), 12, 24, 48, 72, 96, 120, 144, 168, 336 and 504 h, using a PerkinElmer spectrum 100 spectrometer. The device was set to scan in a range of (450 to 4000) $\mathrm{cm}^{-1}$, with a scanning frequency number of 32 and $4 \mathrm{~cm}^{-1}$ resolution. Background scanning was made prior to samples' scanning. The tests were run in duplicates to ensure repeatability of results. The repeatability was measured by the percent of error with a maximum value of $11 \%$. The isokinetic temperature of bitumen binders is recorded to be $100{ }^{\circ} \mathrm{C}$ [1]. At this temperature, the oxidation activation energies are independent on the binder source. For this reason, the oven-ageing temperature was selected to be $100{ }^{\circ} \mathrm{C}$ to eliminate the binder source effects. Additionally, at $100{ }^{\circ} \mathrm{C}$ temperature, the bitumen suffers detectable ageing at short time periods since the temperature lies within the pressurized ageing vessel (PAV) testing temperature range $\left(90-110^{\circ} \mathrm{C}\right)[35]$. 
Omairey, Zhang, Al-Malaika, Sheena, Gu

\section{Data Analysis and Result Discussions}

\subsection{FTIR Data Analysis of AACs}

Figure 1 shows the FTIR results for two replicates of unaged control bitumen samples. There is a considerable difference between the two replicates at the carbonyl and sulfoxide functional groups areas (peaks $1700 \mathrm{~cm}^{-1}$ and $1031 \mathrm{~cm}^{-1}$, respectively), even though they were prepared at identical conditions from the same binder source. This suggests the area between two valleys (the range between 1820 to $1650 \mathrm{~cm}^{-1}$ and 1080 to $980 \mathrm{~cm}^{-1}$, for carbonyl and sulfoxide, respectively) are not representative measures for oxidation. Those two functional groups are particularly important for developing the prediction models of long-term oxidative ageing of bitumen binders and asphalt mixtures, which currently make use of plain parameters of carbonyl area $(C A)$ and sulfoxide area $(S A)$. This can cause serious errors in predicting the oxidative ageing based on those parameters alone. Similar variations were obtained for the AAC-modified duplicate samples, and this variation is mainly attributed to the differences in sample film thickness which causes divergence in absorption percentages, and partially due to the heterogeneity nature of the bitumen. Such variations cannot necessarily be solved by making several trials then measure the mean areas under the peak, in fact by doing so, the results will be rather random since the film thickness is more visible on the wave's lengths than the actual functional group. This leads further to the aim of this research, which is to find a reliable measure for the oxidative ageing of the modified bitumen by AACs.

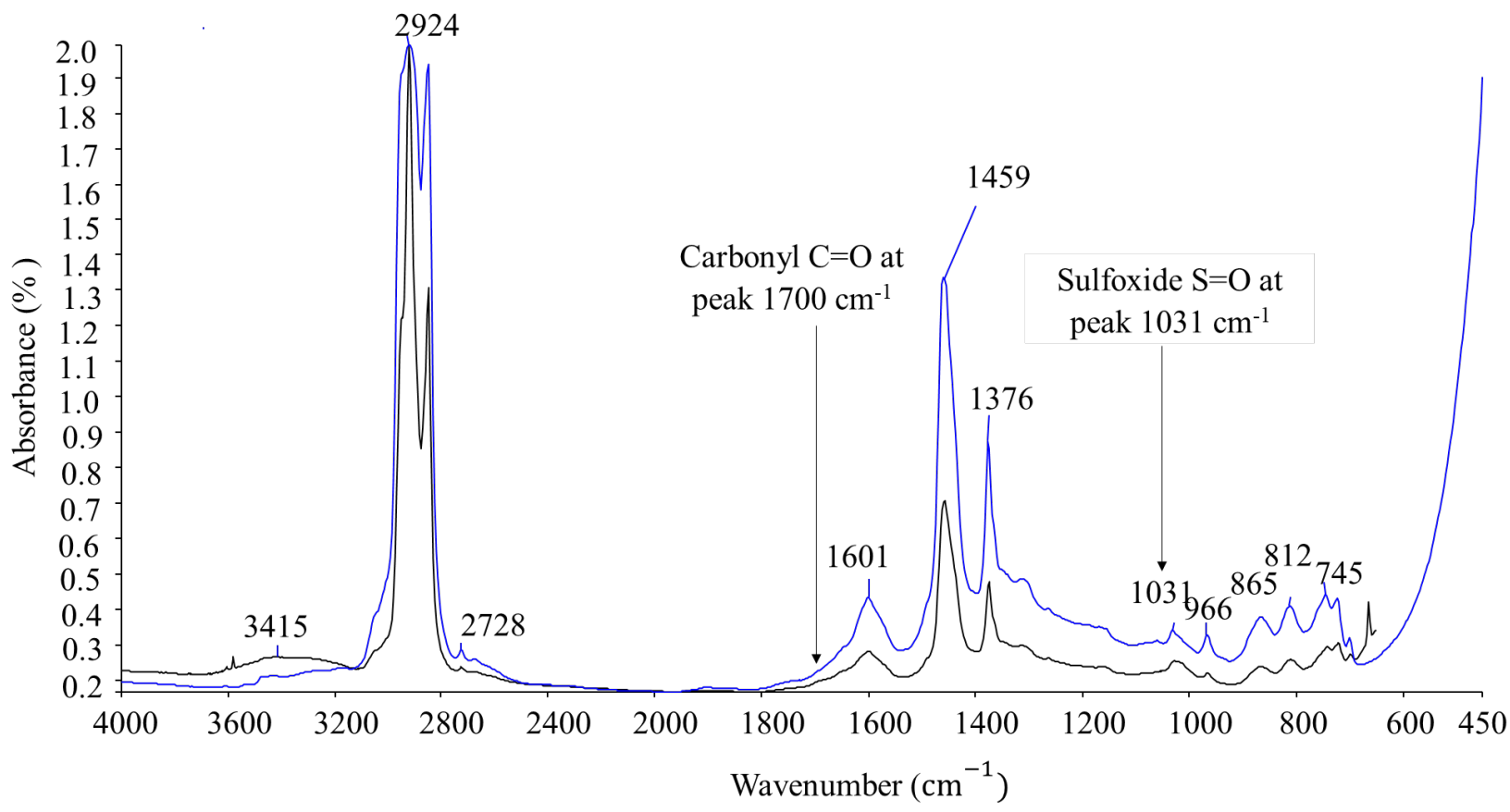

\section{FIGURE 1 FTIR spectrum of control bitumen samples (no additives) at a complete wave range of $(450-4000) \mathrm{cm}^{-1}$.}

Figure 2 shows the FTIR spectrum for the control bitumen sample after different oven ageing periods. The figure shows no peaks in the carbonyl range (1820 to $\left.1650 \mathrm{~cm}^{-1}\right)$ for the unaged bitumen. This suggests that considering a constant range $\left(1820\right.$ to $\left.1650 \mathrm{~cm}^{-1}\right)$ for the carbonyl area can cause errors or obtain negative values for $C A$ for that spectrum without a peak in the carbonyl 
Omairey, Zhang, Al-Malaika, Sheena, Gu

234 range. The current study examined each absorption curve individually to set appropriate ranges for both $C A$ and $S A$ by connecting the left valley's bottom of the peak to the right valley's bottom.

Noticeable and gradual growth in carbonyl area along the ageing period can be seen in Figure 3, in contrast to the sulfoxide, which stabilized with time after an initial sudden growth at the first 24 hours of ageing. This behaviour matches with the findings of Zhao et al. (2010) and Ma et al. (2012) who used Rolling Thin Film Oven (RTFO) ageing protocol in which they studied the ageing properties of SBS polymer modified bitumen [4, 13].

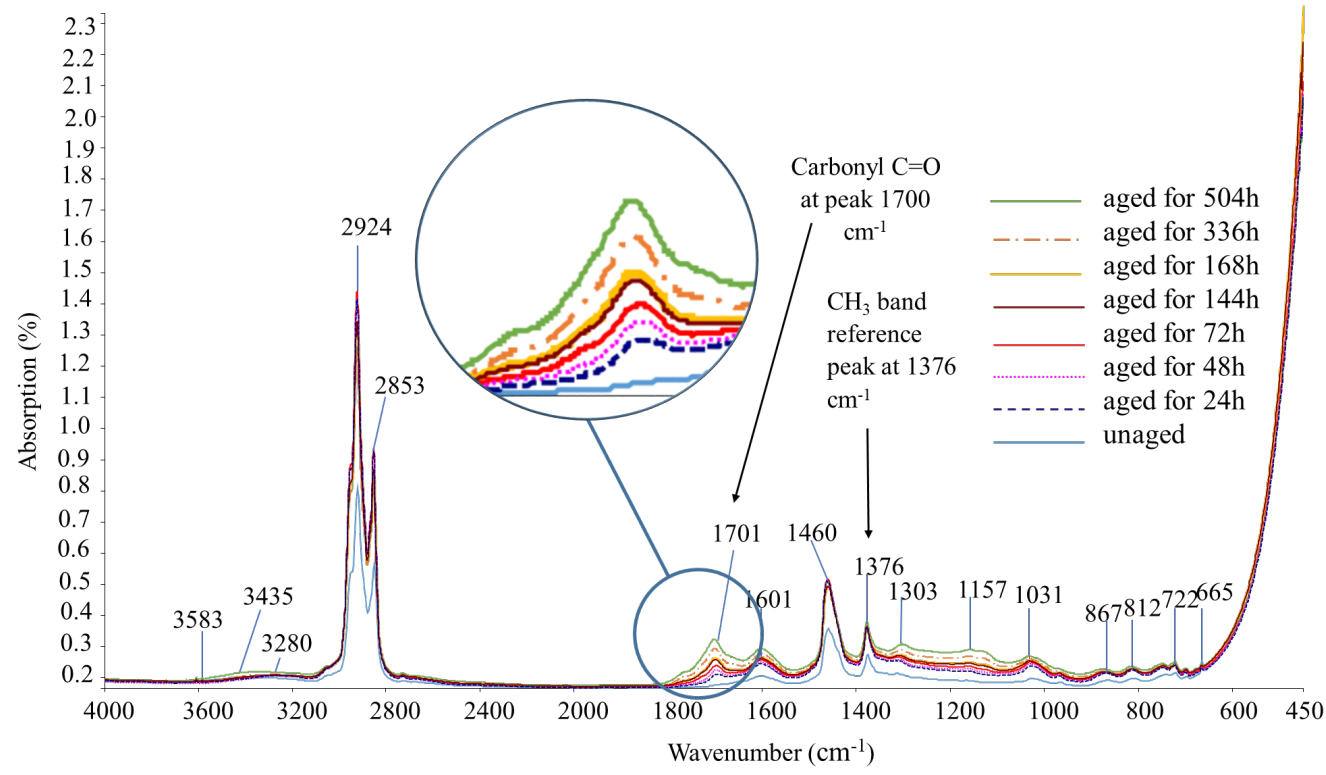

FIGURE 2 FTIR spectrum of control bitumen sample (no additives) for different ages, at a complete waves range of $(450-4000) \mathrm{cm}^{-1}$.

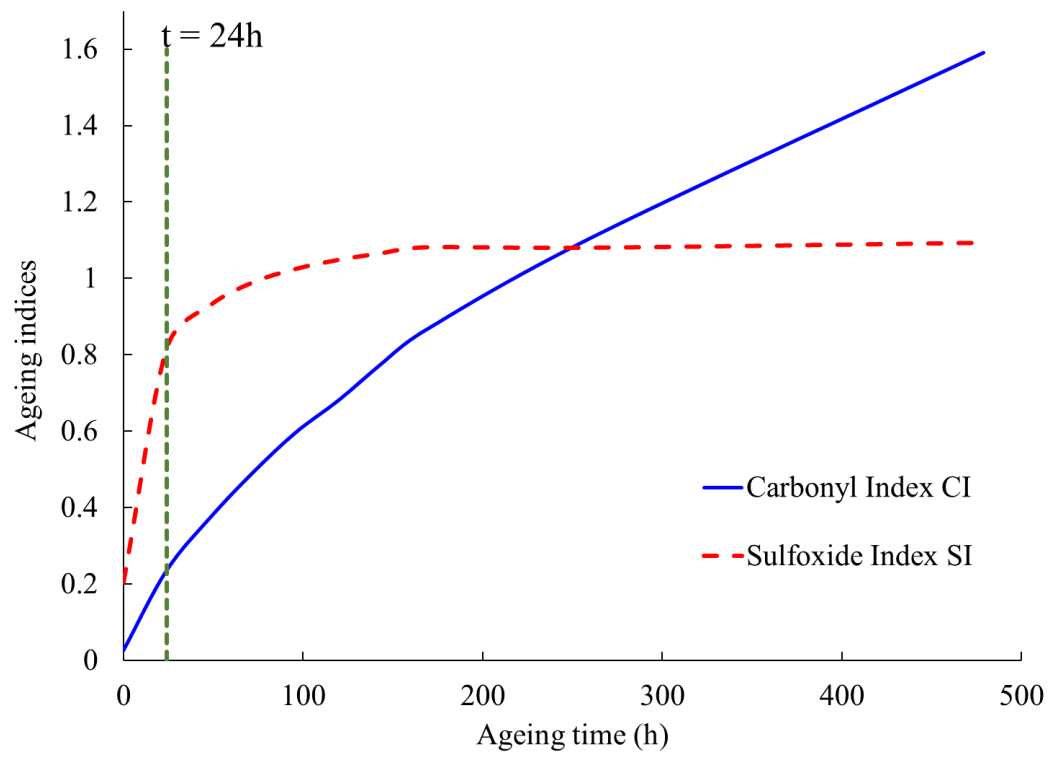

FIGURE 3 Carbonyl and sulfoxide indices of control bitumen sample (no additives) measured with respect to the reference peak $1377 \mathrm{~cm}^{-1}$ versus the oven ageing time. 
To eliminate the sample film thickness effect on the ageing parameters $(C A$ and $S A)$ between samples, a reference peak was used to determine the relative increase of the ageing (compared to the unaged bitumen) due to the extension of the ageing period. The Reference peaks can be determined from Figure 2 as those functional groups' peaks that maintained their areas unchanged during ageing.

From the bitumen spectrum's footprint, some peaks can be distinguished, peak $2924 \mathrm{~cm}^{-1}$ has shoulders of $2853 \mathrm{~cm}^{-1}$ and $2953 \mathrm{~cm}^{-1}$, these belong to alkyl C-H functional group. Although this range was used by several studies as a reference peak [13], it can cause errors due to its high absorption percentage compared to the carbonyl. Whereas peak $1601 \mathrm{~cm}^{-1}$ is shouldered with carbonyl, therefore it is an inaccurate measure to use.

Other recognizable peaks are $1460 \mathrm{~cm}^{-1}, 1377 \mathrm{~cm}^{-1}$ and $813 \mathrm{~cm}^{-1}$ representing $\mathrm{CH}_{2}$ alkanes, $\mathrm{CH}_{3}$ alkanes and aromatics, respectively. Carbonyl index $(\mathrm{Cl})$ is developed based on Equation (1) with respect to these three different peaks. Patterns of the carbonyl index obtained using those three reference peaks were compared in Figure 4.

$$
C I=\frac{C A}{\text { Area under reference peak }}
$$

Where, $C I$ is carbonyl index that is the ratio of the carbonyl area (area under peak $1700 \mathrm{~cm}^{-1}$ ) to the area under a reference peak at the same ageing period, measured in the same unit of absorption from the FTIR tests.

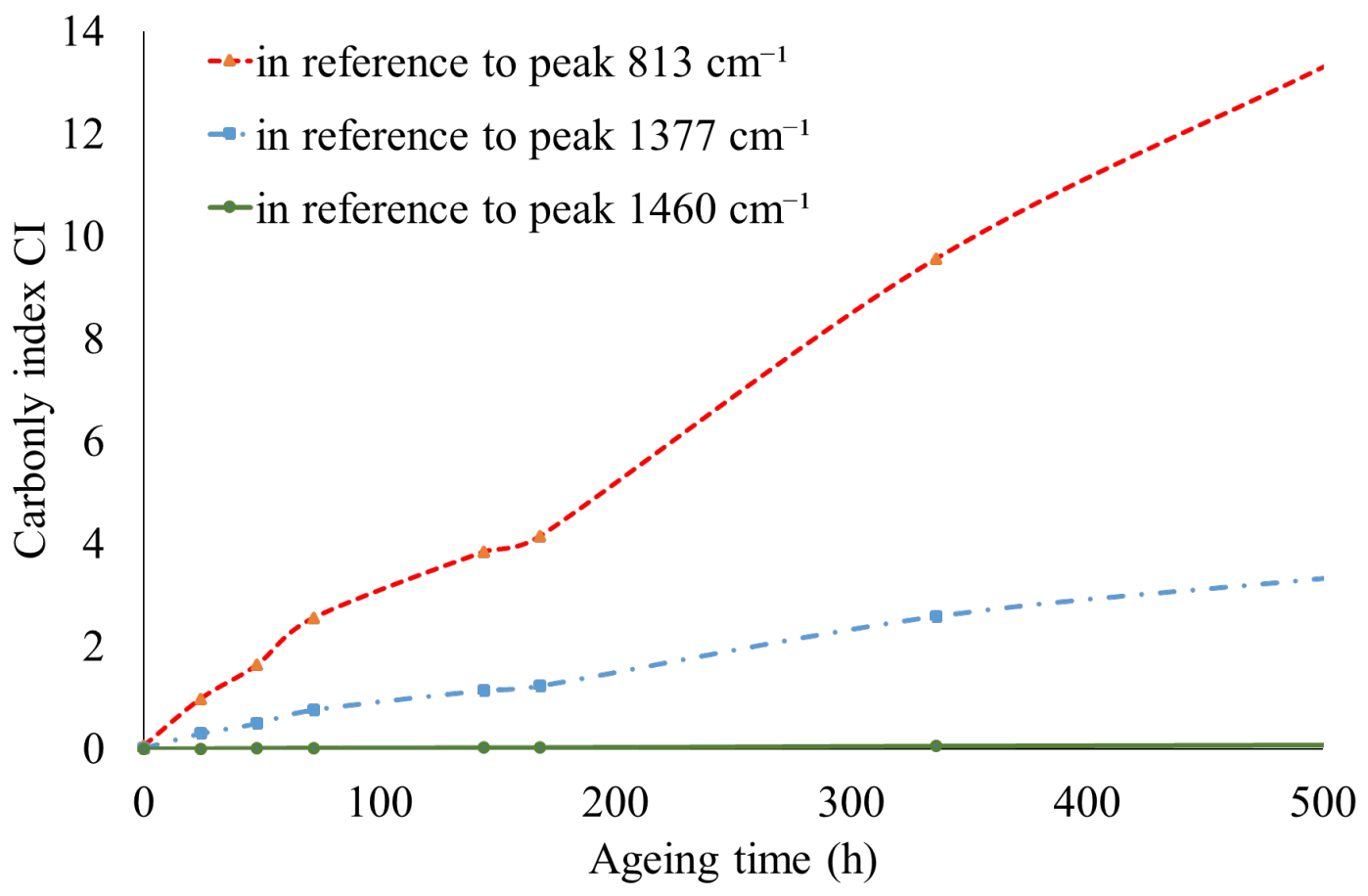


Peak $1377 \mathrm{~cm}^{-1}$ has been chosen as a reference due to its relatively compatible height compared to the carbonyl peak, which causes fewer errors. More importantly, it maintained a consistently stable condition when bitumen was mixed with other additives. On the other hand, $1460 \mathrm{~cm}^{-1}$ peak seemed to be less stable during the initial ageing period particularly with additives containing aromatics, such as Irganox acid, Irganox 1076, MD1024 and calcium hydroxide. Finally, $813 \mathrm{~cm}^{-1}$ peaks may interfere with the polymer modifiers functional groups, thus was not selected.

Figure 5 shows the sulfoxide index $(S I)$ (ratio of the area under peak $1031 \mathrm{~cm}^{-1}$ to the area under the reference peak at the same ageing period, refer to Equation (2)) of the control sample which has no additives. $S I$ had the same pattern of $C I$ at different reference peaks, but unlike carbonyl, sulfoxide's growth rate started to decline after 24 hours of ageing at $100{ }^{\circ} \mathrm{C}$.

$$
S I=\frac{S A}{\text { Area under reference peak }}
$$

No attempts were made here to compare ageing conditions in the laboratory to that in the field, since there is an extensive literature addressing this issue [36-39], and it is not the purpose here to investigate the quantitative issues of oxidative ageing but rather the quality of these measurements. Therefore, this research will focus on carbonyl growth alone without tracking the sulfoxide, but the findings can be generalized for both of the oxidation products.

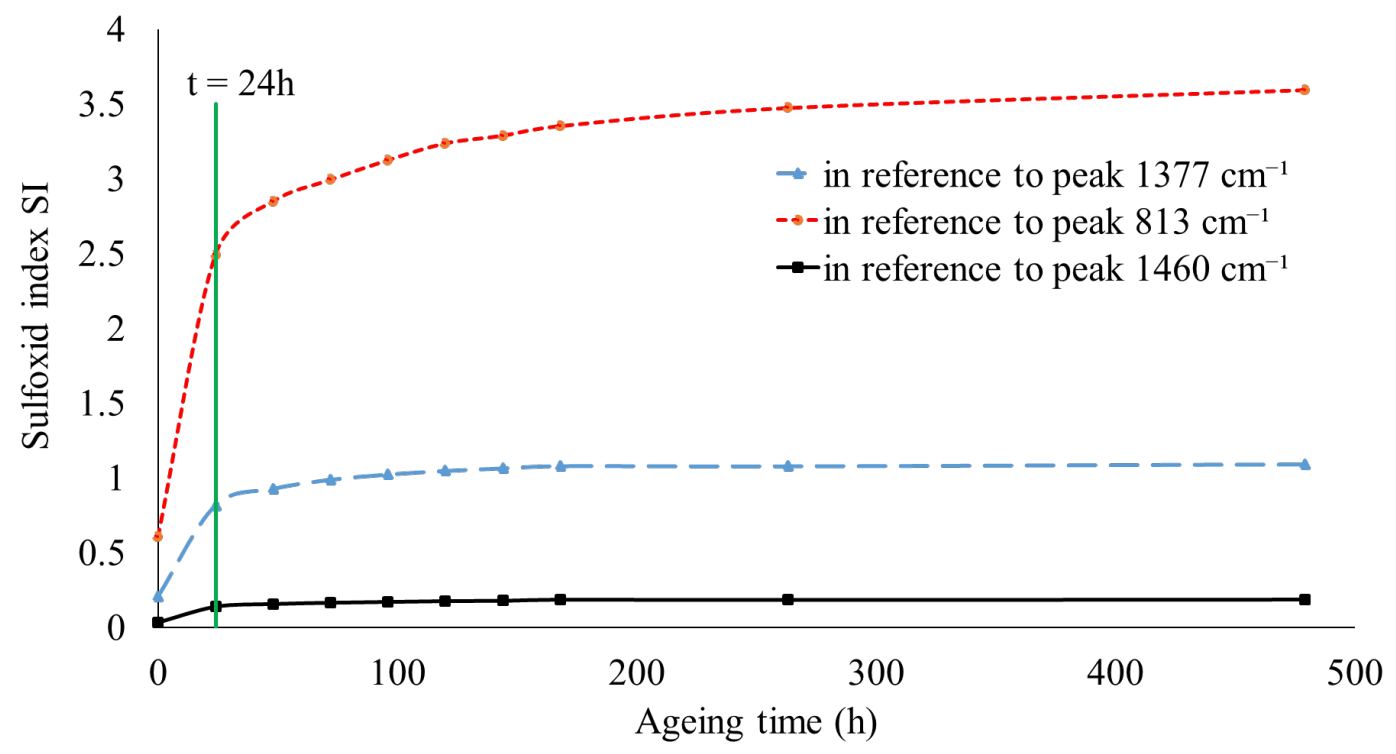

\section{FIGURE 5 Sulfoxide index at different ageing periods for bitumen without additives (control sample).}

The initial values of $C I$ (shown in Figure 4) prior to oven ageing were approximately zero due to the lack of carbonyl functional groups in the virgin bitumen. However, this is not necessarily the case for different bitumen sources. It is also very common to encounter carbonyl and sulfoxide in the virgin bitumen due to the ageing in the early processing, refining, and mixing operations [40] (refer to $\mathrm{t}=0$ in Figure 5). Therefore, for comparison purposes, $C I$ or SI plotted against ageing 
time may not serve the purpose of comparing the anti-oxidation performance of the materials with different initial conditions.

Likewise, the carbonyl index plotted against ageing time for the AAC-modified bitumen cannot be utilized as an AAC selection criterion due to the inherent existence of the carbonyl functional group in these compounds. Figure 6 shows the $C I$ for the AAC-modified and unmodified bitumen versus oven-ageing time at $100^{\circ} \mathrm{C}$. It is clear that the $C I$ values have different initial values and can decrease when AAC-modified bitumen ages. Thus, the $C I$ cannot be directly used for comparing the AAC-modified bitumen in terms of its anti-ageing performance.

To overcome the drift at the initial values of the $C I$, another term was adopted to compare the efficiency of AACs, called the Normalized Carbonyl Index NCI, which is presented as the ratio of the difference between carbonyl index at any ageing time $C I_{t}$ and that before ageing $C I_{o}$ to the carbonyl index at time zero $C I_{o}$ (Equation 3).

$$
N C I=\frac{C I_{t}-C I_{o}}{C I_{o}}
$$

According to Equation (3), the value of $N C I$ will start from zero when the ageing period is zero, regardless of the chemical composition of the bitumen-additive admixture. The NCI can drop later with ageing to become a negative value. This has been observed for the AAC-modified bitumen specimens that contained carbonyl in their chemical composition prior to any ageing. During ageing, this carbonyl decrease led to a drop in $N C I$, causing negative values, as shown in Figure 6(b).
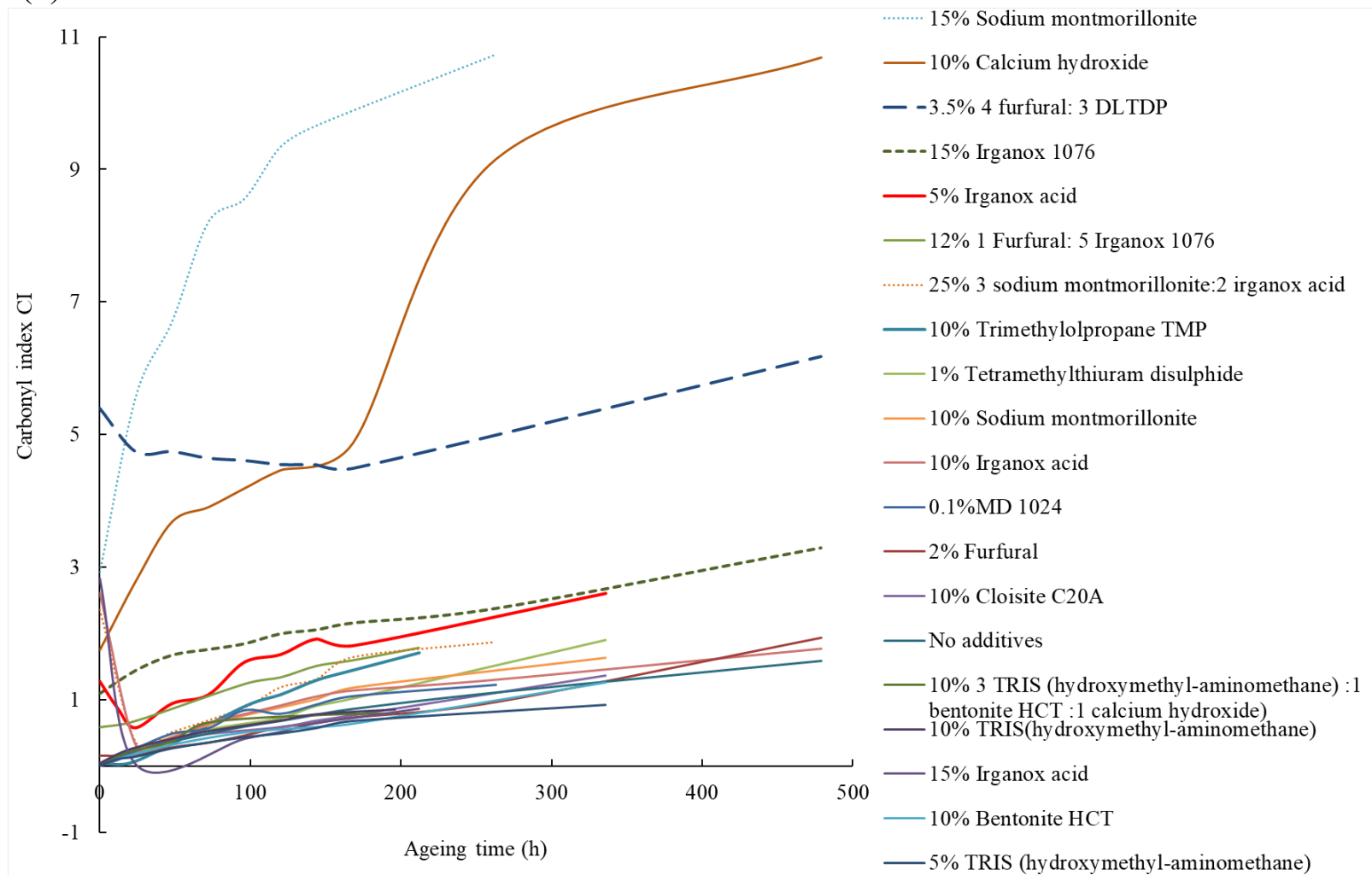
unmodified (control) samples measured by reference peak $1377 \mathrm{~cm}^{-1}$. 
It can be seen from Figures 7 ( $\mathrm{a}$ and $\mathrm{b}$ ) which show the $N C I$ against ageing time for all samples, AAC can be divided (according to their anti-ageing effectiveness) into three categories, namely 1) negative AACs which accelerate the ageing of bitumen, 2) non-effective AACs which do not alter the ageing of bitumen significantly and 3) positive AACs which inhibit the formation of carbonyl and reduce bitumen ageing.

Negative additives included sodium montmorillonite, low concentrations of TRIS and the combination of TRIS with nanomaterials and calcium hydroxide. Generally, all the tested nanomaterials didn't show any positive impacts (inhibiting the carbonyl formation) on the binder's ageing. This may be attributed to the samples' nature. Since the bitumen samples were thin-film slides and they are assumed to be completely exposed to air oxidation. Therefore, the nanomaterials added to the bitumen will introduce no resistance to the oxygen diffusion in the bitumen sample. Therefore, the additives that work towards reducing diffusion will have no effect on such type of samples, and further study is needed on the anti-ageing mechanism of the nanomaterials on the bitumen.

Non-effective additives that didn't contribute to ageing included TMP additive, calcium hydroxide and $10 \%$ concentration of TRIS, as the bitumen modified with those additives show comparable growth of the NCI to the control virgin bitumen. However, increasing TRIS concentration in the binder from 5 to $10 \%$ led to a minor decrease in ageing progression.

Positive additives that proved effective in reducing bitumen's ageing include Irganox 1076, furfural, DLTDP with furfural combination and 10\% and 15\% of Irganox acid, which are shown as the overlapped curved at the bottom of Figure 7(a) that are separately illustrated in Figure 7(b). The bitumen modified by those additives have shown a significant reduction in the growth of the NCI compared to that of the control virgin bitumen. 
Omairey, Zhang, Al-Malaika, Sheena, Gu

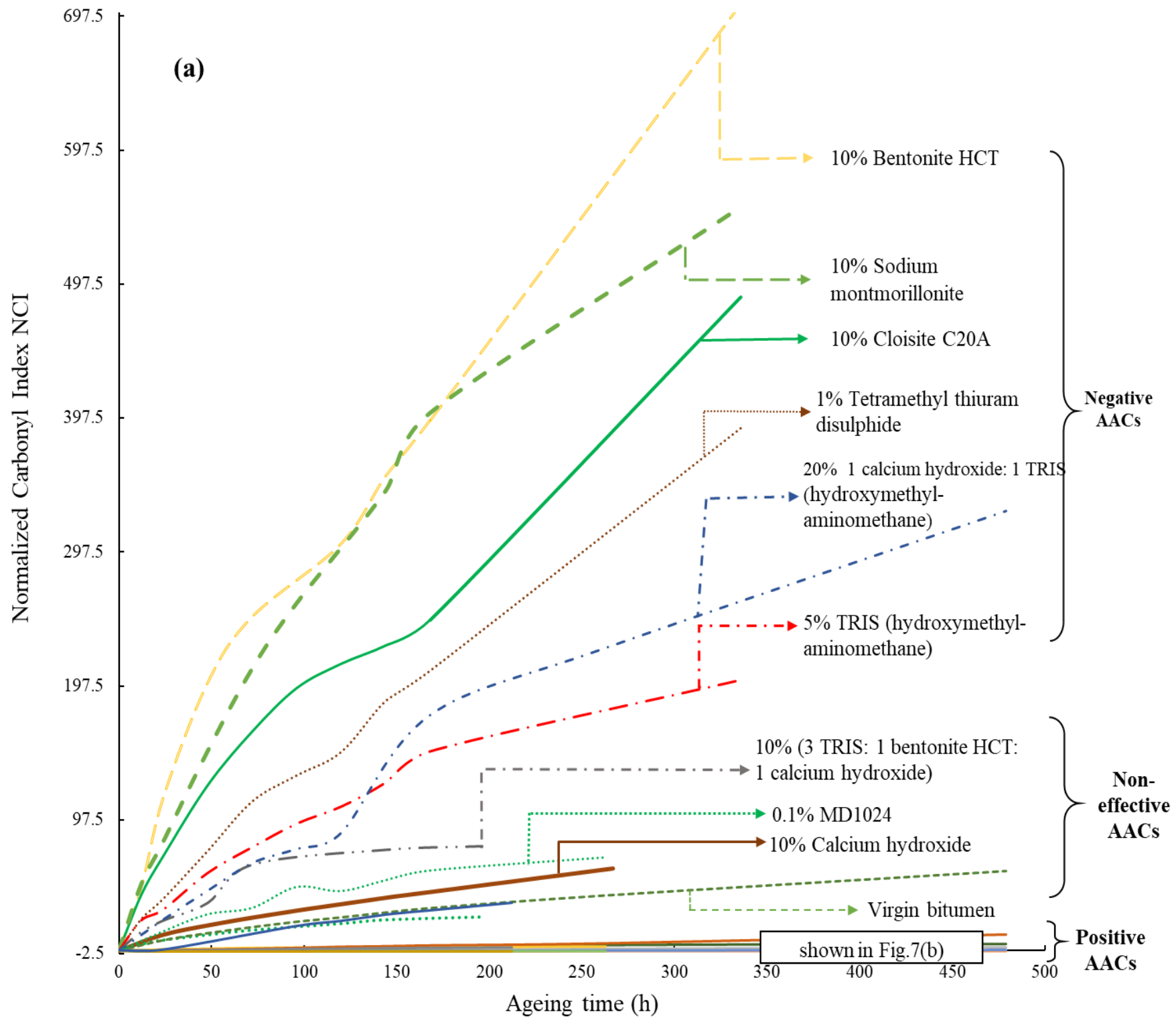


Omairey, Zhang, Al-Malaika, Sheena, Gu

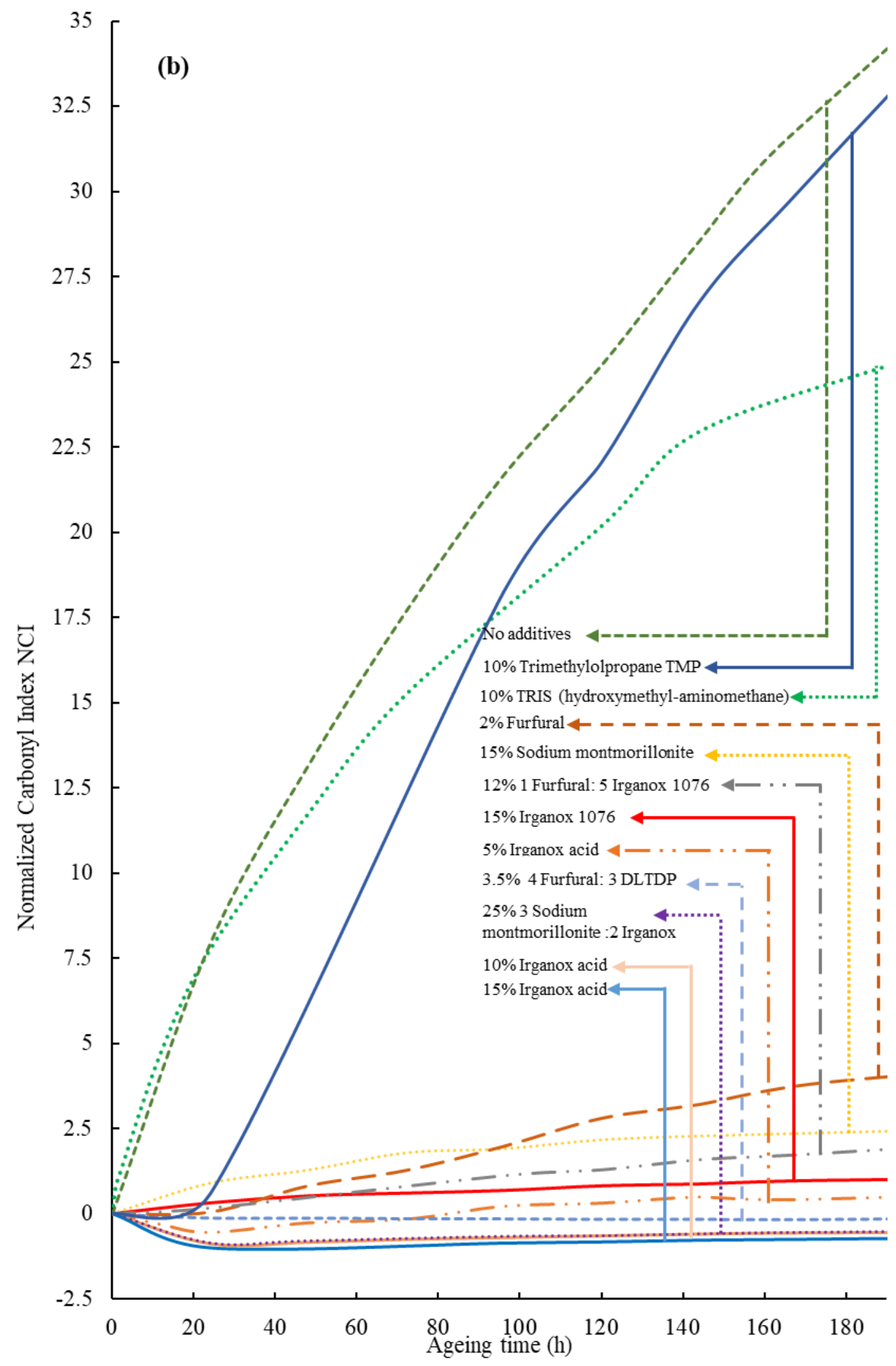


Omairey, Zhang, Al-Malaika, Sheena, Gu

FIGURE 7 Normalized carbonyl index against ageing time at $100{ }^{\circ} \mathrm{C}$ for $\mathrm{AAC}$-modified and unmodified (control) samples measured by reference peak $1377 \mathrm{~cm}^{-1}$ (a) all samples, (b) bitumen samples with positive anti-ageing AACs.

\subsection{Ageing Kinetics Analysis of the AAC-modified Bitumen}

To further compare the anti-ageing performance of different AACs, the ageing kinetics of the AAC-modified bitumen samples were investigated using Equations (4) and (5) which model the fast-term and constant-term ageing, respectively [39]. The following models have been formulated to determine the ageing rate of the binders from different sources.

$$
\begin{gathered}
\frac{d C A}{d t}=M k_{f} e^{-k_{f} t} \\
\frac{\partial C A}{\partial t}=A_{C} P^{\alpha} e^{\frac{-E_{C}}{R T}}
\end{gathered}
$$

and,

$$
k_{f}=A_{f} P^{\alpha} e^{-\frac{E_{f}}{R T}}
$$

Where, $C A$ is the carbonyl area; $M$ is the limiting amount of the carbonyl formation due to the first order reaction following the hot mix production; $A_{f}$ and $A_{c}$ are frequency factors for fast-term and constant-term ageing, and they are bitumen-type dependent, measured by (1/day) units; $P$ is the partial pressure of oxygen, taken to be $0.2 \mathrm{~atm}$ in the atmosphere since the experimental ageing conditions are in the atmosphere and didn't cause any pressure changes; $\alpha$ is the reaction order due to oxygen partial pressure; $E_{\mathrm{f}}$ and $E_{c}$ are the activation energies for both ageing stages; $T$ is the absolute temperature measured in $\mathrm{K}$; $t$ is ageing time (days); $R$ is the universal gas constant which equals $8.314 \mathrm{~J} / \mathrm{K} / \mathrm{mol}$ and $k_{f}$ is a reaction constant which depends on the pressure and temperature.

It can be observed from the ageing pattern of the control sample, the carbonyl formation is time-dependent throughout the entire ageing period, suggesting the binder is still in the fast-term ageing stage. Therefore, Equation (4) can be formulated by replacing $C A$ with $N C I$ to model the fast-term ageing of the bitumen modified with the AACs, resulting in Equation (7).

$$
\frac{d N C I}{d t}=M k_{f} e^{-k_{f} t}
$$

Since the pressure was kept constant during the testing and $\alpha$ is bitumen-type dependent, then the Equation can be simplified by using the term $A f^{\prime}$ (using an earlier approach for modelling oxidation, proposed by Lau et al. (1992) [41].

$$
A_{f}^{\prime}=A_{f} P^{\alpha}
$$

According to Jin (2012) [42], the fast-term frequency factor and activation energy are related by,

$$
A_{f}^{\prime}=2.031 e^{0.3076 E_{f}}
$$

Substituting Equation (9) into Equation (6) produces Equation (10), which can be used along with Equation (7) to determine the rate of $N C I$;

$$
k_{f}=2.031 e^{0.3076 E_{f}} e^{-\frac{E_{f}}{R T}}
$$


375 By applying the curve-fitting approach to the testing data using Equation (11), $k_{f}$ and $M$ can be 376 obtained. Then by employing Equation (10), $E_{f}$ will be determined.

$377 \quad N C I=M\left(a-e^{-k_{f} t}\right)$

378 Where $a$ equal $1 \pm 0.02$, is the initial error resulting from the curve fitting process. $M$ value is a 379 binder source-related parameter [43]. Since one type of bitumen is used in this study, therefore the 380 variations in $M$ and $k_{f}$ values are a result of the AACs inclusion.

It is noteworthy to mention that there is a significant difference in the activation energy $E_{f}$ , $M$ and $k_{f}$ compared with that in the literature. This is due to that the oxidation quantity is measured by the normalized carbonyl index $(N C I)$ instead of the carbonyl area. Therefore, the model coefficients vary accordingly. However, the relationship between the $A_{f}$ and $E_{f}$ values in Equation (9) is still valid since $A_{f}$ is not related to the oxidation rate but rather to the oxygen partial pressure and binder source, particularly since the oxygen pressure is $0.2 \mathrm{~atm}$ which is the same as the conditions attained in literature.

Table 3 shows the modified oxidation kinetics parameters which were obtained by fitting the data into Arrhenius exponential expression in Equation (11), with a coefficient of determination $R^{2}$ of more than 0.95 for most of the samples excluding bitumen sample with $2 \%$ furfural and $1.2 \%$ DLTDP (which achieved $R^{2}$ of 0.77 ) due to its low oxidation rate. In addition, two samples (10\% and 15\% of Irganox acid modified bitumen) didn't show any signs of oxidation initiation thus didn't fit to the Arrhenius model for fast-term ageing (Equation 11). On the contrary, the carbonyl amount characterised by NCI remained unchanged along the entire ageing period, which indicates an excellent anti-ageing performance of the AACs.

TABLE 3 Oxidation kinetics model coefficients for all tested AAC modified bitumen samples

\begin{tabular}{|c|c|c|c|c|c|}
\hline AAC modified bitumen samples & $\begin{array}{l}M \\
(1 / \text { day })\end{array}$ & $k_{f}(1 /$ day $)$ & $\begin{array}{l}E_{f} \\
(\mathrm{~kJ} / \mathrm{mol})\end{array}$ & $R^{2}$ & $\begin{array}{l}\text { Effectiveness } \\
\text { of the AACs }\end{array}$ \\
\hline 10\% Trimethylolpropane TMP & 95.576 & 0.98 & 49 & 0.9888 & \multirow{7}{*}{$\begin{array}{l}\text { Negative AACs } \\
\text { (increase the } \\
\text { ageing of virgin } \\
\text { bitumen) }\end{array}$} \\
\hline $\begin{array}{l}10 \%(3: 1: 1) \text { TRIS (hydroxymethyl- } \\
\text { aminomethane): bentonite HCT: } \\
\text { calcium hydroxide }\end{array}$ & 85.106 & 0.351 & 119 & 0.9830 & \\
\hline $15 \%$ Sodium montmorillonite & 2.635 & 0.336 & 122 & 0.9940 & \\
\hline $\begin{array}{l}\text { 10\% TRIS (hydroxymethyl- } \\
\text { aminomethane) }\end{array}$ & 27.448 & 0.286 & 133 & 0.9953 & \\
\hline 5\% Irganox acid & 2.101 & 0.154 & 175 & 0.9761 & \\
\hline $10 \%$ Sodium montmorillonite & 674.762 & 0.124 & 190 & 0.9988 & \\
\hline $\begin{array}{l}\text { 5\% TRIS (hydroxymethyl- } \\
\text { aminomethane) }\end{array}$ & 246.71 & 0.116 & 194 & 0.9961 & \\
\hline $10 \%$ Calcium hydroxide & 92.539 & 0.088 & 213 & 0.9453 & \multirow{6}{*}{$\begin{array}{l}\text { Non-effective } \\
\text { AACs } \\
\text { (not alter the } \\
\text { ageing of virgin } \\
\text { bitumen) }\end{array}$} \\
\hline $\begin{array}{l}\text { Virgin bitumen with no additives } \\
\text { (control) }\end{array}$ & 72.48 & 0.076 & 222 & 0.9962 & \\
\hline $12 \%(1: 5)$ furfural: Irganox 1076 & 4.413 & 0.075 & 223 & 0.9953 & \\
\hline $\begin{array}{l}20 \%(1: 1) \text { calcium hydroxide: TRIS } \\
\text { (hydroxymethyl-aminomethane) }\end{array}$ & 542.013 & 0.049 & 253 & 0.9839 & \\
\hline $10 \%$ Cloisite C20A & 1402.732 & 0.046 & 257 & 0.9833 & \\
\hline 15\% Irganox 1076 & 3.023 & 0.045 & 258 & 0.9710 & \\
\hline
\end{tabular}


Omairey, Zhang, Al-Malaika, Sheena, Gu

\begin{tabular}{|c|c|c|c|c|c|}
\hline $0.1 \%$ MD 1024 & 238.879 & 0.033 & 278 & 0.9703 & \\
\hline $10 \%$ Bentonite $\mathrm{HCT}$ & 1275.739 & 0.031 & 283 & 0.9803 & \\
\hline 1\% Tetramethylthiuram disulphide & 1391.963 & 0.023 & 305 & 0.9972 & \multirow{6}{*}{$\begin{array}{l}\text { Positive AACs } \\
\text { (reduce the } \\
\text { ageing of virgin } \\
\text { bitumen) }\end{array}$} \\
\hline $2 \%$ Furfural & 1214.963 & 0.001 & 567 & 0.9914 & \\
\hline $\begin{array}{l}\text { 25\% 3:2) sodium montmorillonite: } \\
\text { Irganox acid }\end{array}$ & 216.349 & 0.001 & 596 & 0.9653 & \\
\hline $3.5 \%$ (4:3) furfural: DLTDP & 132.086 & 0.001 & 664 & $0.7672 *$ & \\
\hline $10 \%$ Irganox acid* & -- & -- & -- & -- & \\
\hline 15\% Irganox acid* & -- & -- & -- & -- & \\
\hline
\end{tabular}

Samples in Table 3 are arranged according to their fast-term activation energy in ascending order. Samples of small activation energies tend to have fast oxidation, while those with greater oxidation energies are expected to have better anti-ageing performance, namely the later develop fewer carbonyl compounds under the accelerated ageing conditions. Samples like $10 \%$ and $15 \%$ Irganox acid that performed superiorly compared to others didn't fit to the modelled equation because they didn't show any signs of ageing under $100{ }^{\circ} \mathrm{C}$ oven temperature conditions for a thin-film binder at ambient atmospheric pressure. Based on this observation, it is recommended to use activation energy to group the AACs in terms of their effectiveness in antiageing performance. Those AACs with activation energy below $200 \mathrm{~kJ} / \mathrm{mol}$ are negative AACs as they will increase the ageing (quantified by the formation of carbonyl compounds) of the virgin bitumen and those above $300 \mathrm{~kJ} / \mathrm{mol}$ are positive AACs as they will decrease the ageing of the virgin bitumen. Those between 200 and $300 \mathrm{~kJ} / \mathrm{mol}$ are non-effective AACs since they do not alter the ageing of the virgin bitumen.

There was a great variation in $M$ values for the tested specimens which can be attributed to the chemical composition of the additives. Furthermore, some of the AACs contained carbonyl functional groups in their primary form prior to ageing. Figure 8 ( $a$ and $b$ ) shows the chemical composition of Irganox acid and DLTDP, where a well-defined peak for the carbonyl functional groups can be observed at waves peak from 1710 to $1737 \mathrm{~cm}^{-1}$. This AAC-induced carbonyl functional groups led to the negative values on the initial portion of the NCI vs ageing time curves, especially during the ageing period less than one day ( $t=1$ day). This portion was neglected in the curve-fitting process since it makes nonsense to fit the negative $N C I$ values to the suggested ageing kinetics model in Equation (11). Logically, this affects the $M$ values. Therefore, $M$ values cannot be used as an ageing indicator for the screening purposes of variable AAC additives to evaluate the anti-ageing performance of the AAC modified bitumen. 
Omairey, Zhang, Al-Malaika, Sheena, Gu

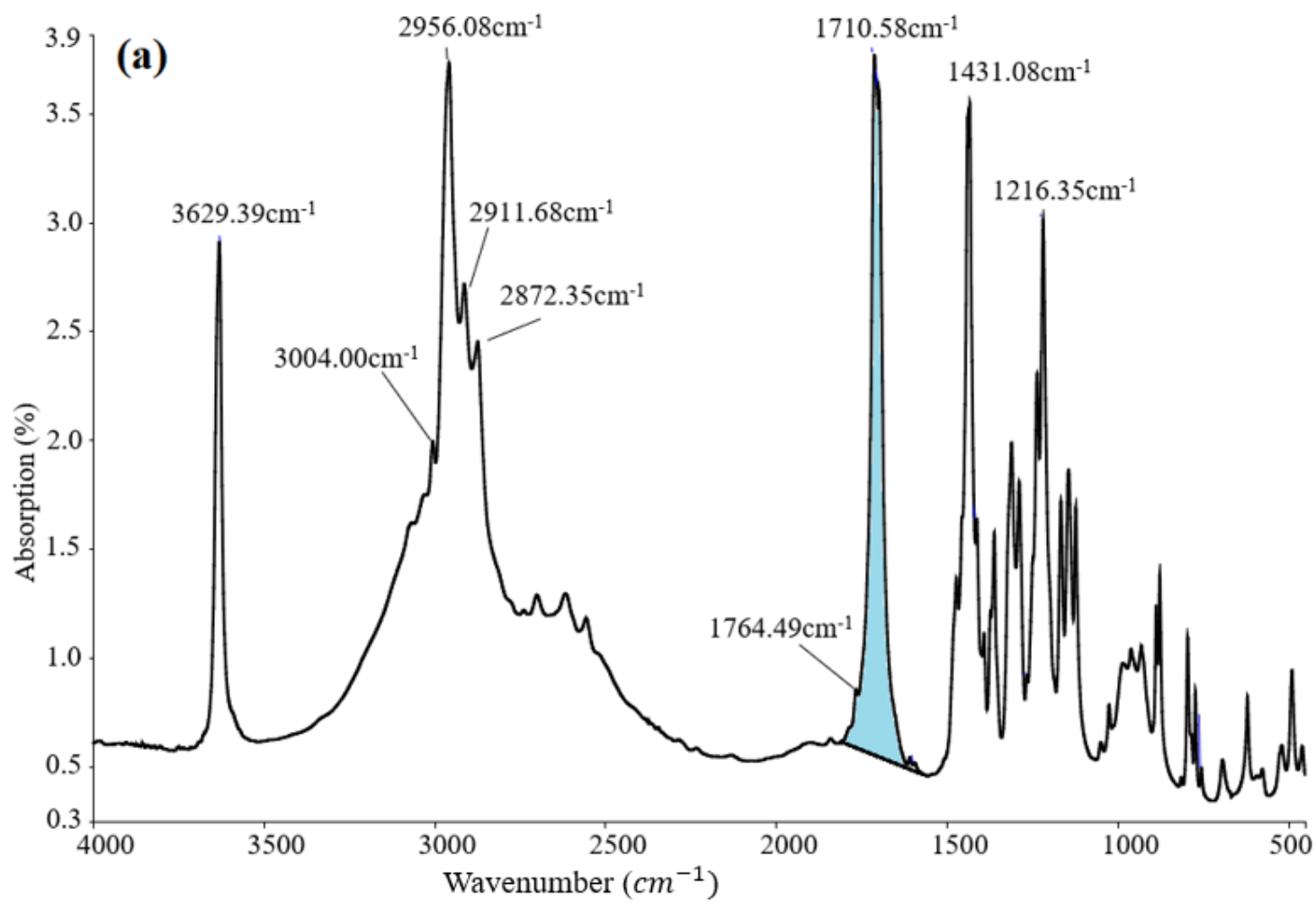

Wavenumber $\left(\mathrm{cm}^{-1}\right)$

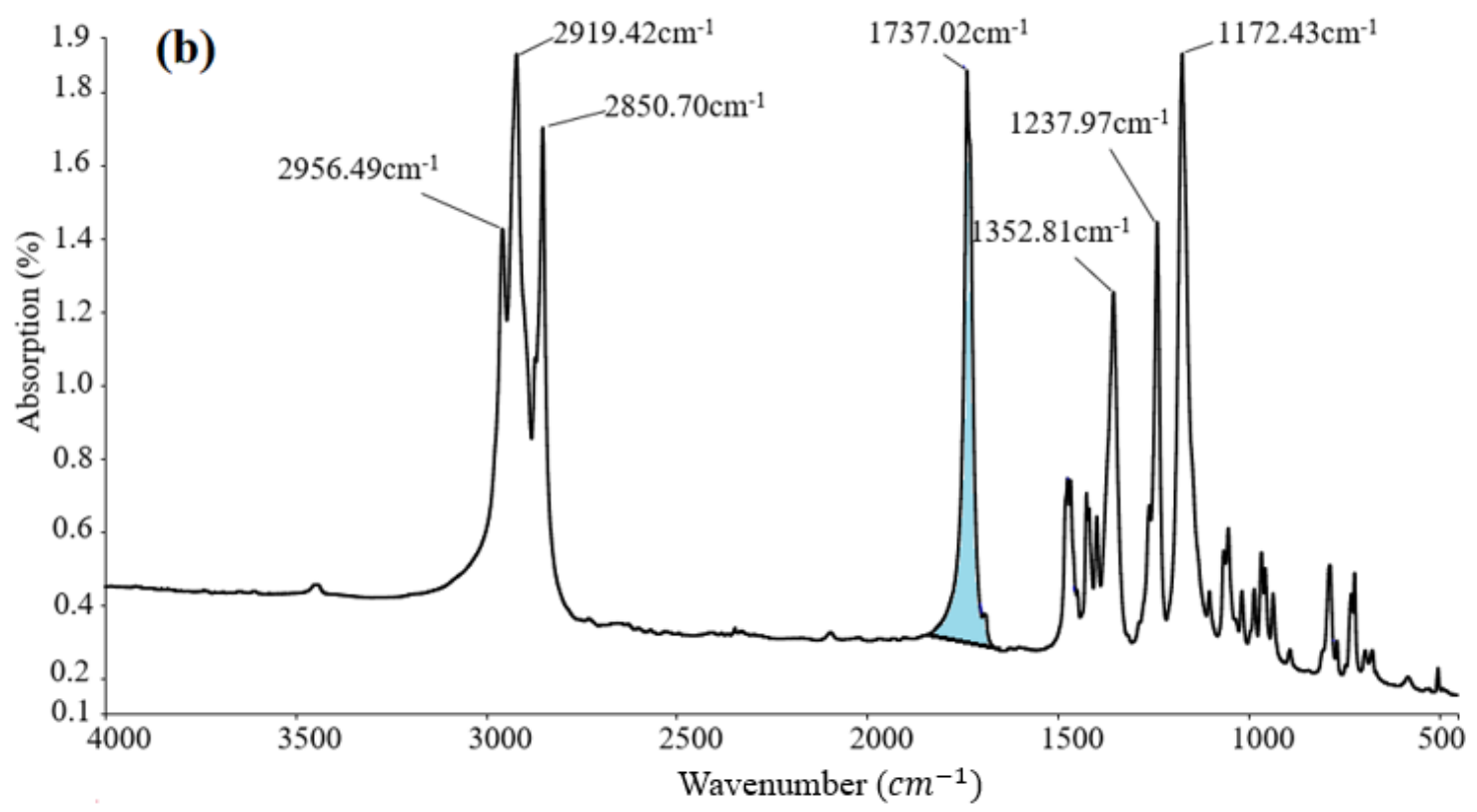

FIGURE 8 FTIR spectrum of (a) Irganox acid and (b) DLTDP at a complete waves range of $(450-4000) \mathrm{cm}^{-1}$

According to the activation energy based AAC categories obtained in Table 3, the negative AACs lead to a drop in the oxidation energy of binders thus increased the oxidative ageing susceptibility, which are sodium montmorillonite, Tris and $\mathrm{Ca}(\mathrm{OH})_{2}$. For the non-effective AACs, 
431 it appears that adding those AAC does not alter the bitumen's ageing performance, such as a low concentration of 5\% by binder's weight of Irganox acid, Irganox 1076, C20A, and 0.1\% MD 1024. Nano-additives such as bentonite and Tetramethylthiuram disulphide are also non-effective AACs which appeared to cause an insignificant increase in the activation energy.

The positive AACs exhibited a high anti-ageing performance by increasing the oxidation energy of the bitumen and those positive AACs were those containing furfural, Irganox acid with sodium montmorillonite, furfural with DLTDP, and high concentrations of Irganox acid (10\% or more). The exact amount of increase in $E_{f}$ for Irganox acid was beyond measure at current testing conditions, where bitumen with Irganox acid didn't show any signs of carbonyl development. In sum, with the aid of activation energy based AAC categories and the proposed NCI as the ageing characterisation parameter, it can be concluded that this $N C I$ and activation energy based ageing evaluation approach has proved convenience and effective as an initial screening method for antiageing compounds for bitumen.

\section{Conclusions}

This paper investigates the effect of anti-ageing compounds (AACs) on the oxidation kinetics of bitumen using FTIR tests. Up to 20 different AACs were added to bitumen binder and subjected to laboratory oven ageing conditions at $100^{\circ} \mathrm{C}$ for a range of ageing durations. The results indicated the followings:

1) A reference peak (at $1377 \mathrm{~cm}^{-1}$ wavelength) was identified to determine the carbonyl index to quantify the ageing in bitumen, due to its relatively comparable height to the carbonyl which causes fewer errors. An advantage of using the peak at $1377 \mathrm{~cm}^{-1}$ lies in that it remained unchanged when bitumen was modified by different AACs and aged for different durations.

2) The carbonyl content measured using carbonyl areas $(C A)$ under the waves range (1820$1650 \mathrm{~cm}^{-1}$ ) or any other fixed ranges, was found unsuitable for the oxidative ageing quantification of bitumen. It cannot be used to compare the ageing of the formulated samples because of specimens' disparities in terms of bitumen sources, AAC types and sample thickness. Using a fixed waves range may cause negative values for $C A$, especially for the unaged binders or short-term aged samples. Therefore, the wave range should be inspected for each sample.

3) Carbonyl index (CI, defined as the ratio of the carbonyl area to the reference peak area) was ineffective in evaluating AACs' anti-ageing performance. This is due to that some bitumen binders and AACs anti-oxidants contain carbonyl in their initial formulas, thus $C I$ versus ageing time for those compounds may start from a non-zero $C I$ value, resulting in a non-comparable growth rate between bitumen modified by different AACs.

4) Normalized carbonyl index $(N C I)$ was proposed to quantify the oxidative ageing of bitumen modified by AACs. It eliminates the impact of the initial carbonyl content of the binders or AACs, thus manifests the carbonyl growth rate to evaluate the AACs' antiageing performance. It was found that $N C I$ can be used to formulate the ageing kinetics of the AAC-modified bitumen, where kinetics model coefficients $M, K_{f}$ and $E_{f}$ values were obtained using the data of NCI vs. ageing time. 
Omairey, Zhang, Al-Malaika, Sheena, Gu

5) The activation energy $E_{f}$ was found to be capable of the differentiating the anti-ageing efficiency of the AACs. Those AACs with $E_{f}$ below $200 \mathrm{~kJ} / \mathrm{mol}$ are negative as they will increase the ageing (quantified by the formation of carbonyl compounds) of the virgin bitumen and those above $300 \mathrm{~kJ} / \mathrm{mol}$ are positive AACs as they will decrease the ageing of the virgin bitumen. Those between 200 and $300 \mathrm{~kJ} / \mathrm{mol}$ are non-effective AACs since they do not alter the ageing of the virgin bitumen.

6) Samples that exhibited high anti-ageing performance were those contained furfural, Irganox acid with sodium montmorillonite, furfural with DLTDP, and high concentrations of Irganox acid (10\% or more).

This study proposed an initial screening and analysing methodology to evaluate the anti-ageing efficiency of the AACs when used in bitumen. This method can provide a primary screening of the additives' effectiveness at reducing the ageing rate of the modified bitumen, however, it should be followed by further laboratory rheological and mechanical tests on the AAC modified bitumen with different binder sources in future studies.

\section{Acknowledgement}

This work is partially supported by the Schlumberger Foundation as part of the Faculty for the Future Fellowship Program. Additionally, the authors would like to acknowledge the partial financial support from the European Commission's Horizon 2020 programme via a Marie S. Curie Individual Fellowship (Grant No. 749232).

\section{References}

1. Liu, M., Lunsford, K., Davison, R., Glover, C. and Bullin, J. (1996). The kinetics of carbonyl formation in asphalt. AIChE Journal, 42(4), pp.1069-1076.

2. Glover, C.J., Han, R., Jin, X., Prapaitrakul, N., Cui, Y., Rose, A., Lawrence, J.J., Padigala, M., Arambula, E., Park, E.S. and Martin, A.E., 2014. Evaluation of binder ageing and its influence in ageing of hot mix asphalt concrete: Technical report (No. FHWA/TX-14/0-6009-2). Texas A \& M Transportation Institute.

3. Ma, T., Zhao, Y., Huang, X. and Zhang, Y., 2016. Characteristics of desulfurized rubber asphalt and mixture. KSCE Journal of Civil Engineering, 20(4), pp.1347-1355.

4. Ma, T., Huang, X., Zhao, Y. and Yuan, H., 2012. Aging behaviour and mechanism of SBS-modified asphalt. Journal of Testing and Evaluation, 40(7), pp.1186-1191.

5. Ma, T., Huang, X. M., Mahmoud, E. and Garibaldy, E., 2011. Effect of moisture on the aging behavior of asphalt binder. International Journal of Minerals, Metallurgy, and Materials, 18(4), p.460.

6. Hou, X., Lv, S., Chen, Z. and Xiao, F., 2018. Applications of Fourier transform infrared spectroscopy technologies on asphalt materials. Measurement, 121, pp.304-316

7. Cui, Y., Glover, C.J., Braziunas, J. and Sivilevicius, H., 2018. Further exploration of the pavement oxidation model-Diffusion-reaction balance in asphalt. Construction and Building Materials, 161, pp.132-140.

8. Herrington, P.R., 2012. Diffusion and reaction of oxygen in bitumen films. Fuel, 94, pp.86-92. 
Omairey, Zhang, Al-Malaika, Sheena, Gu

9. Liu, H.Y., Zhang, H.L., Hao, P.W. and Zhu, C.Z., 2015. The effect of surface modifiers on ultraviolet ageing properties of nano-zinc oxide modified bitumen. Petroleum Science and Technology, 33(1), pp.72-78.

10. Lamontagne, J., Dumas, P., Mouillet, V. and Kister, J., 2001. Comparison by Fourier transform infrared (FTIR) spectroscopy of different ageing techniques: application to road bitumens. Fuel, 80(4), pp.483-488.

11. Yao, H., You, Z., Li, L., Lee, C.H., Wingard, D., Yap, Y.K., Shi, X. and Goh, S.W., 2012. Rheological properties and chemical bonding of asphalt modified with nanosilica. Journal of Materials in Civil Engineering, 25(11), pp.1619-1630.

12. Ma, T., Wang, H., He, L., Zhao, Y., Huang, X. and Chen, J., 2017. Property characterization of asphalt binders and mixtures modified by different crumb rubbers. Journal of Materials in Civil Engineering, 29(7), p.04017036.

13. Zhao, Y., Gu, F., Xu, J. and Jin, J., 2010. Analysis of ageing mechanism of SBS polymer modified asphalt based on Fourier transform infrared spectrum. Journal of Wuhan University of Technology-Mater. Sci. Ed., 25(6), pp.1047-1052.

14. Zhang, Y., Birgisson, B. and Lytton, R.L., 2015. Weak form equation-based finiteelement modelling of viscoelastic asphalt mixtures. Journal of Materials in Civil Engineering, 28(2), p.04015115.

15. Li, J., Zhang, J., Qian, G., Zheng, J. and Zhang, Y., 2019. Three-dimensional simulation of aggregate and asphalt mixture using parameterized shape and size gradation. Journal of Materials in Civil Engineering, 31(3), p.04019004.

16. Yu, J., Zeng, X., Wu, S., Wang, L. and Liu, G., 2007. Preparation and properties of montmorillonite modified asphalts. Materials Science and Engineering: A, 447(1-2), pp.233-238.

17. You, Z., Mills-Beale, J., Foley, J.M., Roy, S., Odegard, G.M., Dai, Q. and Goh, S.W., 2011. Nanoclay-modified asphalt materials: Preparation and characterization. Construction and Building Materials, 25(2), pp.1072-1078.

18. Apeagyei, A.K., 2011. Laboratory evaluation of antioxidants for asphalt binders. Construction and Building Materials, 25(1), pp.47-53.

19. Plancher, H., Green, E.L. and Petersen, J.C., 1976. Reduction of oxidative hardening of asphalts by treatment with hydrated lime-A mechanistic study. Association of Asphalt Paving Technologists Proc, 45, pp.1-24.

20. Dickinson, E.J., 1984. The diffusion-controlled reaction of oxygen with films of bituminous binders. Australian Road Research, 14(3).

21. Edler, A.C., Hattingh, M.M., Servas, V.P. and Marais, C.P., 1985. Use of ageing tests to determine the efficacy of hydrated lime additions to asphalt in retarding its oxidative hardening (with discussion). Association of Asphalt Paving Technologists Proc, 54, pp. 118-139.

22. Petersen, J.C., 2009. A review of the fundamentals of asphalt oxidation: chemical, physicochemical, physical property, and durability relationships. Transportation Research E-Circular, (E-C140). 
Omairey, Zhang, Al-Malaika, Sheena, Gu

23. Ameri, M., Kouchaki, S. and Roshani, H., 2013. Laboratory evaluation of the effect of nano-organosilane anti-stripping additive on the moisture susceptibility of HMA mixtures under freeze-thaw cycles. Construction and Building Materials, 48, pp.1009-1016.

24. Gu, F., Ma, W., West, R.C., Taylor, A.J. and Zhang, Y., 2019. Structural performance and sustainability assessment of cold central-plant and in-place recycled asphalt pavements: A case study. Journal of Cleaner Production, 208, pp.1513-1523.

25. Ghile, D.B. (2006). Effects of nanoclay modification on rheology of bitumen and on performance of asphalt mixtures. Delft University of Technology.

26. Ortega, F.J., Navarro, F.J., García-Morales, M. and McNally, T., 2017. Effect of shear processing on the linear viscoelastic behaviour and microstructure of bitumen/montmorillonite/MDI ternary composites. Journal of industrial and engineering chemistry, 48, pp.212-223.

27. Kumar, A. and Suman, S.K., 2017. Experimental Investigations on Nanoclay (Cloisite15A) Modified Bitumen. World Academy of Science, Engineering and Technology, International Journal of Civil, Environmental, Structural, Construction and Architectural Engineering, 11(2), pp.172-177.

28. Hassan, Z., Hassan, D., Rezvan, B. and Ali, A., 2012. Influence of bentonite additive on bitumen and asphalt mixture properties. World Academy of Science, Engineering and Technology, 6.

29. Yao, H., You, Z., Li, L., Goh, S.W., Lee, C.H., Yap, Y.K. and Shi, X., 2013. Rheological properties and chemical analysis of nanoclay and carbon microfiber modified asphalt with Fourier transform infrared spectroscopy. Construction and Building Materials, 38, pp.327-337.

30. Ferington, T.E. and Tobolsky, A.V., 1955. Organic disulphide as initiators of polymerization: tetramethyl thiuram disulphide. Journal of the American Chemical Society, 77(17), pp.4510-4512.

31. Wilkes, M.F. and Davies, M.C., Lubrizol Corp, 2010. Asphaltene inhibition. U.S. Patent 7,795,183.

32. Yunus, R., Fakhru'l-Razi, A., Ooi, T.L., Iyuke, S.E. and Perez, J.M., 2004. Lubrication properties of trimethylolpropane esters based on palm oil and palm kernel oils. European journal of lipid science and technology, 106(1), pp.52-60.

33. Li, R., Xiao, F., Amirkhanian, S., You, Z. and Huang, J., 2017. Developments of nanomaterials and technologies on asphalt materials-A review. Construction and Building Materials, 143, pp.633-648.

34. Yang, Y., Zhang, Y., Omairey, E., Cai, J., Gu, F. and Bridgwater, A.V., 2018. Intermediate pyrolysis of organic fraction of municipal solid waste and rheological study of the pyrolysis oil for potential use as bio-bitumen. Journal of Cleaner Production, 187, pp.390-399.

35. ASTM D6521-18, Standard Practice for Accelerated Ageing of Asphalt Binder Using a Pressurized Ageing Vessel (PAV), ASTM International, West Conshohocken, PA, 2018, www.astm.org 
Omairey, Zhang, Al-Malaika, Sheena, Gu

36. Bell, C.A., AbWahab, Y., Cristi, M.E. and Sosnovske, D., 1994. Selection of laboratory ageing procedures for asphalt-aggregate mixtures (No. SHRP-A-383). Strategic Highway Research Program.

37. Airey, G.D., 2003. State of the art report on ageing test methods for bituminous pavement materials. International Journal of Pavement Engineering, 4(3), pp.165-176.

38. Cui, Y., Jin, X., Han, R. and Glover, C.J., 2014. An accelerated method for determining asphalt oxidation kinetics parameters for use in pavement oxidation and performance modelling. Petroleum Science and Technology, 32(22), pp.2691-2699.

39. Jin, X., Cui, Y. and Glover, C.J., 2013. Modelling asphalt oxidation in pavement with field validation. Petroleum Science and Technology, 31(13), pp.1398-1405.

40. Zafari, F., Rahi, M., Moshtagh, N. and Nazockdast, H., 2014. The improvement of Bitumen properties by adding nanoSilica. Study of Civil Engineering and Architecture.

41. Lau, C.K., Lunsford, K.M., Glover, C.J., Davison, R.R. and Bullin, J.A., 1992. Reaction rates and hardening susceptibilities as determined from pressure oxygen vessel ageing of asphalts. Transportation Research Record, (1342).

42. Jin, X. (2012). Asphalt oxidation kinetics and pavement oxidation modelling. Texas A\&M University.

43. Herrington, P.R., 1998. Oxidation of bitumen in the presence of a constant concentration of oxygen. Petroleum science and technology, 16(7-8), pp.743-765. 